\title{
Implantação da gestão por processos em uma pequena empresa de base tecnológica: diferencial de competitividade
}

Marina Magalhães Longo Staino

marina.staino@gmail.com

Priscila Souza Uatanabe

priscilauatanabe@gmail.com

Jaqueline Akemi Suzuki

jaqueakemi@hotmail.com

Adriana Ferreira de Faria

adrianaf@ufv.br

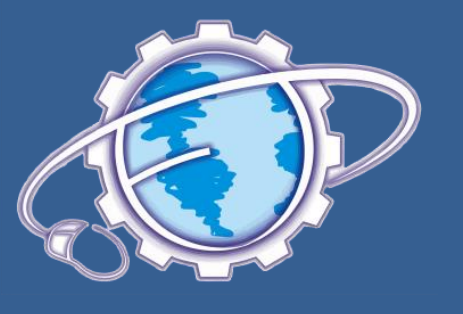

\section{RESUMO}

Em um cenário cada vez mais competitivo, as empresas de pequeno porte necessitam inovar organizacionalmente para se manterem no mercado e alcançarem bom controle dos seus processos produtivos. As decisões tomadas pelas organizações devem ser baseadas em dados e fatos que possam ser obtidos através das ferramentas da qualidade. Dessa forma, este artigo teve como objetivo geral a descrição da implantação da gestão por processos em uma pequena empresa de base tecnológica, de acordo com a norma ISO 9001 . O desenvolvimento do projeto permitiu identificar a realidade e as dificuldades em se implantar a gestão por processos, bem como as melhorias que a metodologia proporciona em toda a organização.

Palavras-chave: Sistema de gestão da qualidade, Mapeamento de processos, Gestão por processos.

\section{Process management implementation in a small technology based business enterprise: competitive differential}

\begin{abstract}
In an everyday more competitive scenario, the small business enterprises need to innovate in organizational terms to remain in the market and reach a good control of their productive processes. The decisions taken by the organizations must be based on data and facts which may be obtained through the quality tools. In light of that, this article has the objective to describe the implementation of process management in a small technology based business, according to the ISO 9001 regulations. The project development enables the identification of the difficulties which occur in the implementation of the process management, as well as the identification of the improvements which the methodology offers to the overall organization.
\end{abstract}

Keywords: Quality management system; process mapping; process management. 


\section{Introdução}

Diante de um mercado cada vez mais competitivo e globalizado, as pequenas empresas precisam investir em inovação organizacional para permanecerem no mercado e obterem, assim, um bom controle de seus processos produtivos, de forma a refletir diretamente nos clientes suas melhorias em qualidade, custos, cumprimento de prazos e segurança. De acordo com Slack et al. (2002), há uma crescente conscientização de que bens e serviços de alta qualidade permitem que uma organização apresente considerável vantagem competitiva. Dessa forma, garantir produtos e, ou, serviços com a qualidade assegurada é essencial para a sobrevivência das organizações.

A solução encontrada por empresas é investir em um sistema de qualidade, conforme os requisitos normativos da ISO 9001. De acordo com Carpinetti et al. (2007), em alguns casos essas certificações são necessárias, uma vez que são exigidas pelo próprio cliente; em outras situações, mesmo que isso não ocorra, a implementação criteriosa dos requisitos de gestão estabelecidos na norma elevará a eficácia e eficiência da empresa, tornando-a mais competitiva.

Para a implantação de sistemas de gestão da qualidade, conforme as normas ISO é necessário atentar para os princípios estabelecidos pela norma, como foco no cliente, liderança, abordagem factual para a tomada de decisão, abordagem sistêmica, abordagem por processos, relação benéfica com fornecedores e melhoria contínua.

As empresas devem tomar decisões baseadas em fatos e dados, os quais podem ser obtidos por meio das ferramentas da qualidade. Para identificar os processos-chave de uma organização, deve ser realizado um estudo de todas as atividades que fazem parte da rotina de trabalho da empresa, de forma crítica e sem omissões. Realizado este estudo, os dados devem ser transformados em informações que demonstrem uma visão sistêmica do fluxo de materiais e informações. Este trabalho é denominado mapeamento dos processos. $\mathrm{O}$ mapeamento de processos é um instrumento da área da qualidade, que não necessita de grandes investimentos em tecnologia. Colenghi (2007) afirmou que os Procedimentos Operacionais Padrão têm como finalidade garantir, mediante a padronização, as saídas esperadas por cada processo executado. A padronização é um método que permite reduzir a variabilidade de um processo.

Considerando a importância da abordagem por processo para a implantação de sistemas de gestão da qualidade, este trabalho teve como objetivo geral abordar o caso de implantação da gestão por processos em uma pequena empresa de base tecnológica. Primeiramente, foi dada atenção especial para análise do ambiente interno da organização; em seguida, teve início a identificação dos processos-chave, para os quais foram elaborados os mapas (fluxogramas). Posteriormente, foram elaborados os procedimentos operacionais e as instruções de trabalho referentes aos processos-chave. A execução desse projeto permitiu identificar a realidade e dificuldades das organizações em implantar a gestão por processos, baseada nos requisitos normativos da ISO 9001, bem como verificar as melhorias ocorridas após as etapas implantadas, como a redução na perca de tempo e de recursos materiais e financeiros decorrentes da diminuição de retrabalhos.

Para a realização deste trabalho na empresa, algumas ferramentas de qualidade foram utilizadas, como: fluxogramas, mapas de processos e checklists. Além disso, reuniões periódicas ocorreram para conscientizar todos os colaboradores envolvidos. Conceitos do programa 5S foram aplicados, com o intuito de facilitar a disseminação da cultura da qualidade.

\section{Revisão de literatura}

O início da história da humanidade já era conectado à qualidade. Sua evolução ocorreu pela exigência de mercado, em que as organizações começaram a se preocupar com seus consumidores, produzindo, assim, produtos e serviços, a fim de satisfazê-los. Assim, criaram-se soluções e conceitos que evoluíram à medida que também evoluíam as gerações, resultando numa busca incessante por uma melhor qualidade de vida (JURAN, 1993). A qualidade dos produtos é determinada pelo desempenho das atividades básicas na cadeia de produção de uma empresa, evidenciando-se que a qualidade do produto depende do bom gerenciamento da organização produtiva.

A evolução do conceito e das técnicas utilizados nos programas de qualidade é apresentada por Garvin (2002), que definiu quatro diferentes "eras da qualidade": da inspeção; do controle estatístico do processo; da garantia da 
qualidade; e da gestão total da qualidade. Suas principais características são encontradas no Quadro 1.

De acordo com Carvalho e Paladini (2005), diversos estudiosos ajudaram a construir a área da qualidade, os chamados "Gurus da Qualidade", que fizeram parte da história tanto pela contribuição teórica quanto pela intervenção em empresas. São eles: Walter A. Shewhart, conhecido pelo desenvolvimento do Controle Estatístico do
Processo (CEP); W. Edwards Deming, responsável pelo desenvolvimento do PDCA (Plan, Do, Check, $A c t$ ); Joseph M. Juran, o qual defendeu três fundamentos: planejamento da qualidade, melhoria e controle; Armand Feigenbaum foi quem definiu o conceito de controle da qualidade total; Philip B. Crosby, que definiu a política da qualidade; Kaoru Ishikawa, que sistematizou instrumentos para controle da qualidade; e Genichi Taguchi, quem atribuiu conceitos para qualidade.

Quadro 1 - Eras da qualidade

\begin{tabular}{|c|c|c|c|c|c|c|}
\hline $\begin{array}{l}\text { Características } \\
\text { Básicas }\end{array}$ & $\begin{array}{l}\text { Interesse } \\
\text { principal }\end{array}$ & $\begin{array}{l}\text { Visão da } \\
\text { Qualidade }\end{array}$ & Ênfase & Métodos & $\begin{array}{l}\text { Papel dos } \\
\text { profissionais da } \\
\text { qualidade } \\
\end{array}$ & $\begin{array}{l}\text { Quemé o } \\
\text { responsável pela } \\
\text { qualidade }\end{array}$ \\
\hline Inspeção & Verificação. & $\begin{array}{l}\text { Um problema a } \\
\text { ser resolvido. }\end{array}$ & $\begin{array}{l}\text { Uniformidade } \\
\text { do produto. }\end{array}$ & $\begin{array}{l}\text { Instrumentos de } \\
\text { medição. }\end{array}$ & \begin{tabular}{|l|} 
Inspeção, \\
classificação, \\
contagem, avaliação \\
e reparo. \\
\end{tabular} & $\begin{array}{l}\text { O departamento } \\
\text { de inspeção. }\end{array}$ \\
\hline $\begin{array}{l}\text { Controle } \\
\text { Estatístico do } \\
\text { Processo }\end{array}$ & Controle. & $\begin{array}{l}\text { Um problema a } \\
\text { ser resolvido. }\end{array}$ & $\begin{array}{l}\text { Uniformidade } \\
\text { do produto, } \\
\text { com menos } \\
\text { inspeção. }\end{array}$ & $\begin{array}{l}\text { Ferramentas } \\
\text { técnicas e } \\
\text { estatísticas. }\end{array}$ & \begin{tabular}{|l|} 
Solução de \\
problemas e a \\
aplicação de \\
métodos \\
estatísticos.
\end{tabular} & $\begin{array}{l}\text { Os departamentos } \\
\text { de fabricação e } \\
\text { engenharia (o } \\
\text { controle da } \\
\text { qualidade). }\end{array}$ \\
\hline $\begin{array}{l}\text { Garantia da } \\
\text { Qualidade }\end{array}$ & Coordenação. & $\begin{array}{l}\text { Um problema a } \\
\text { ser resolvido, } \\
\text { mas que é } \\
\text { enfrentado } \\
\text { proativamente. }\end{array}$ & $\begin{array}{l}\text { Toda cadeia de } \\
\text { fabricação, } \\
\text { des de o projeto } \\
\text { até o mercado, } \\
\text { e a } \\
\text { contribuição de } \\
\text { todos os } \\
\text { grupos } \\
\text { funcionais para } \\
\text { impedir falhas } \\
\text { de qualidade. } \\
\end{array}$ & $\begin{array}{l}\text { Programas e } \\
\text { sistemas. }\end{array}$ & $\begin{array}{l}\text { Planejamento, } \\
\text { medição da } \\
\text { qualidade e } \\
\text { desenvolvimento de } \\
\text { programas. }\end{array}$ & \begin{tabular}{|l} 
Todos os \\
departamentos, \\
com a alta \\
administração se \\
envolvendo \\
superficialmente \\
no planejamento e \\
na execução das \\
diretrizes da \\
qualidade.
\end{tabular} \\
\hline $\begin{array}{l}\text { Gestão Total da } \\
\text { Qualidade }\end{array}$ & $\begin{array}{l}\text { Impacto } \\
\text { Estratégico. }\end{array}$ & $\begin{array}{l}\text { Uma } \\
\text { oportunidade de } \\
\text { diferenciação da } \\
\text { concorrência }\end{array}$ & $\begin{array}{l}\text { As } \\
\text { necessidades } \\
\text { de mercado e } \\
\text { do cliente. }\end{array}$ & $\begin{array}{l}\text { Planejamento } \\
\text { estratégico, } \\
\text { estabelecimento } \\
\text { de objetivos e a } \\
\text { mobilização da } \\
\text { organização. }\end{array}$ & $\begin{array}{l}\text { Estabelecimento de } \\
\text { metas, educação e } \\
\text { treinamento, } \\
\text { consultoria a outros } \\
\text { departamentos e } \\
\text { desenvolvimento de } \\
\text { programas. }\end{array}$ & $\begin{array}{l}\text { Todos na } \\
\text { empresa, com a } \\
\text { alta administração } \\
\text { exercendo forte } \\
\text { liderança. }\end{array}$ \\
\hline
\end{tabular}

Fonte: CARVALHO; PALADINI, 2005.

Segundo $\mathrm{Zu}$ (2009), as organizações implantam a Gestão da Qualidade Total nos seus processos, a fim de dar prioridade a alguns princípios, como: o foco no cliente, melhoria contínua e trabalho em equipe, visando à melhoria da qualidade dos produtos e serviços oferecidos. Independentemente do setor de atuação, as empresas modernas vêm adotando uma estratégia para melhorar os níveis de qualidade $\mathrm{e}$ produtividade. A era da Gestão da Qualidade Total coexiste com um fator social que, envolvido nesse cenário, traz para as organizações novas exigências, entre as quais se destacam o padrão de qualidade de produtos e, ou, serviços ofertados.

Com o objetivo de auxiliar as organizações na implantação de seus sistemas de gestão da qualidade, foram lançadas em 1987 as normas ISO de gestão da qualidade. A International Organization for Standardization (ISO), criada em 1947 na Suíça, tem por objetivo promover o desenvolvimento da normatização em âmbito mundial, facilitando as atividades de troca de produtos e serviços (SARTORELLI, 2003). Uma das normas que compõem a denominada família ISO 9000 é a norma NBR ISO 9001:2008. A norma internacional ISO 9001:2008 foi elaborada para 
estabelecer requisitos para um sistema de gestão da qualidade, em que a organização possa atender aos requisitos de seus clientes, da organização e de regulatórios. Os requisitos da norma ISO 9001:2008 são genéricos e se propõem a serem aplicados a todos os tipos de empresa, através de um conjunto de elementos inter-relacionados.

O certificado ISO 9001 é adquirido por meio de um processo de auditoria de certificação, ou de terceira parte, emitido por uma empresa certificadora, que atesta que o sistema produtivo da organização está apto para gerenciar o atendimento de requisitos dos clientes e atender aos requisitos da norma (SOUZA; MORALLES, 2009).

A certificação ISO 9001 promove o desenvolvimento da normalização e atividades correlatas, com os objetivos de facilitar o comércio internacional de bens e serviços e desenvolver a cooperação nos campos da atividade intelectual, científica, tecnológica e econômica. Além de divulgar documentos que possibilitam práticas aceitas internacionalmente, a intenção dessa norma é garantir estabilidade e uniformidade para um processo produtivo e permitir a busca pela excelência e pela melhoria contínua (SINGLES et al., 2001).

De acordo com Souza e Moralles (2009), entre os diversos conceitos abordados na norma NBR ISO 9001:2008, esta promove a adoção da abordagem de processo para o desenvolvimento, implementação e melhoria da eficácia de um sistema de gestão da qualidade. Nessa abordagem, conforme esses autores, quando utilizada em um sistema de gestão de qualidade, enfatiza a importância de:

- Atendimento aos Requisitos de Clientes: conhecer os requisitos dos clientes permite satisfazer suas necessidades e, dessa forma, garantir a sobrevivência do negócio em um ambiente competitivo. A palavra cliente, para a norma, deve ser interpretada como parte interessada, que são todas as entradas que envolvem os processos da organização.

- Considerar os processos em termos de valor agregado: devem-se definir os processos que agregam valor aos clientes e planejar e desenvolver aqueles que são essenciais para a realização do produto.

- Obtenção de resultados de desempenho e eficácia de processo: garantir que os processos sejam monitorados em todas as etapas de produção, por meio de indicadores, para permitir adequações e melhoria contínua.

- Melhoria contínua de processos: as organizações devem determinar, coletar e analisar dados adequados para controlar os processos e garantir o atendimento aos requisitos dos clientes.

Ainda de acordo com a norma NBR ISO 9001:2008, para implementação de um sistema de qualidade a empresa deve seguir as seguintes etapas:

- Identificar os processos críticos necessários para o sistema de gestão da qualidade e sua aplicação para toda a organização.

- Determinar a sequência e interação desses processos.

- Definir critérios e métodos necessários para assegurar que a operação e o controle desses processos sejam eficazes.

- Assegurar a disponibilidade de recursos e informações necessários para apoiar a operação e monitoramento desses processos.

- Monitorar, medir e analisar esses processos.

- Implementar ações necessárias para atingir os resultados planejados e a melhoria contínua.

Segundo Walter (2009), a ISO 9001:2008 tem como foco a eficácia do sistema de gestão da qualidade para que os requisitos do cliente sejam conhecidos e atendidos. Assim, as etapas do planejamento, de acordo com a metodologia Plan, Do, Check, Act (PDCA) - planejar, realizar, verificar, agir -, constituem instrumento gerencial importante para que o processo se realize em conformidade com as necessidades identificadas para os clientes/usuários e para os produtos/serviços.

Segundo Gonçalves (2000, p. 1), “a definição dos processos básicos é essencial para algumas estratégias de aperfeiçoamento do funcionamento das empresas, já que grupos de recursos serão alocados a eles, tanto para execução como para gestão". A utilização do conceito de processos fornece um conveniente nível de análise, além de possibilitar melhor visão do comportamento gerencial, mais integrada e abrangente. De acordo com Chen et al. (2003), os processos-chave do sistema de qualidade incluem a responsabilidade da direção, gestão de recursos, gestão de processos e medição, análise e melhoria.

De acordo com Gonçalves (2000), é importante identificar o processo como a maneira comum de realizar o trabalho para definir a forma básica de organização das pessoas e demais 
recursos da empresa. O processo é um conceito fundamental no projeto dos meios pelos quais uma empresa pretende produzir e entregar seus produtos e serviços aos seus clientes. Esse autor afirmou que muitos dos processos nas organizações são repetitivos e envolvem, no seu conjunto, a maioria das pessoas da empresa. Os processos podem ser classificados em processos principais ou de apoio. A categorização de um processo está relacionada com a abrangência, integração com as partes interessadas, interferência na qualidade, disponibilidade, continuidade, integridade e segurança do produto. Os processos principais são assim classificados por influenciarem diretamente no negócio da empresa e estarem relacionados ao atendimento das necessidades do cliente. Já os de apoio são aqueles que têm como objetivo garantir a efetividade dos processos principais, dando suporte à execução destes (SOUZA; MORALLES, 2009).

$\mathrm{Na}$ concepção de Campos (1994), "o domínio do processo do trabalho só é possível através da padronização, o que é a mesma coisa que dizer: domine os padrões dos fatores e obterá o resultado esperado". No entendimento desse autor, a padronização do processo de trabalho, principalmente com a rotina bastante conhecida, é fundamental. Dessa forma, a padronização de processos é uma técnica que tem como objetivo reduzir a variabilidade dos processos, sem prejudicar a sua flexibilidade, ou seja, os produtos e serviços devem atender às expectativas dos clientes de forma regular e ao menor custo possível.

De acordo com Lima (2005), um Procedimento Operacional Padrão (POP) é um documento que divulga o planejamento do trabalho repetitivo, que deve ser executado para o alcance da meta-padrão. O POP (SOP - Standard Operation Procedure ou Procedimento- Padrão de Operação) deve conter, quando apropriado: listagem dos equipamentos; peças e material utilizado na tarefa, incluindo-se os instrumentos de medida; padrões da qualidade esperados; descrição dos procedimentos da tarefa por atividades críticas detalhados; condições de fabricação, de operação e pontos proibidos de cada tarefa; pontos de controle (itens de controle e características da qualidade) e os métodos de controle; relação de anomalias passíveis de ação; e roteiro de inspeção periódica dos equipamentos de produção.

Procedimento Operacional Padrão (POP) é um roteiro padronizado, ou seja, é uma descrição detalhada de todas as operações necessárias para a realização de uma atividade. Seu objetivo primário é fazer que as pessoas que executem a mesma atividade a façam de forma uniforme, ou seja, padronizando o processo ou atividade (LIMA, 2005).

\section{Metodologia de pesquisa}

Para o desenvolvimento deste trabalho, foi aplicada a metodologia de gestão por processos em uma empresa localizada em uma das unidades do Centro Tecnológico de Desenvolvimento Regional de Viçosa (CENTEV), a Incubadora de Empresas de Base Tecnológica da Universidade Federal de Viçosa, em Viçosa, MG. A empresa em questão produz equipamentos científicos para o manejo da irrigação e outras aplicações no agronegócio.

As etapas desenvolvidas para realização do projeto foram: 1) Revisão de literatura: consulta a livros, artigos, dissertações de mestrado, revistas e meios eletrônicos referentes aos temas Sistema de gestão da qualidade, ISO 9001 e Gestão por processos; 2) Diagnóstico inicial da organização realizado através de reuniões com todos os envolvidos no processo, por meio de entrevistas direcionadas à coleta de informações, com o intuito de identificar os processos-chave da organização; 3 ) Coleta de informações: acompanhamento dos processos, de forma a documentar as atividades de cada processo e desenvolver o fluxograma, bem como o procedimento operacional padrão; e 4) Validação dos processos padronizados. Nesse contexto, a metodologia de pesquisa utilizada para o desenvolvimento do trabalho trata-se de uma pesquisa-ação.

Para viabilizar essa interação entre teoria e prática, a metodologia de pesquisa adotada ao longo das intervenções foi a pesquisa-ação. Lançada na década de 1940 por Kurt Lewin, essa metodologia apresenta bons resultados em ambientes onde se deseja acoplar pesquisa e ação em um processo no qual os atores - membros representativos da situação investigada - participam, junto com os pesquisadores, para elucidar, de forma interativa, a realidade na qual estão inseridos, identificando problemas coletivos, buscando e experimentando soluções em situação real. Dessa maneira, a produção e utilização do conhecimento acontecem de forma simultânea (THIOLLENT, 1997 apud PROCACI et al., 2010).

A pesquisa-ação é um tipo de pesquisa com base empírica que é concebida e realizada em estreita associação com uma ação ou com a resolução de um problema coletivo e na qual os 
pesquisadores e participantes representativos da situação ou do problema estão envolvidos, de modo cooperativo ou participativo. $\mathrm{Na}$ pesquisa-ação, o pesquisador toma ação (não é mero observador) e, ao mesmo tempo em que soluciona um problema, contribui para a ciência, sendo interativa, pois envolve a cooperação e interatividade entre os envolvidos. Foram realizados diversos métodos de coleta de dados (técnicas quantitativas e qualitativas). Para atingir os objetivos propostos, foi necessário um vasto pré-entendimento do ambiente organizacional, das condições, estrutura e dinâmica das operações da empresa (COUGHLAN, 2002 apud MIGUEL, 2007).

\section{Desenvolvimento do trabalho}

O interesse da empresa na implantação da gestão por processos surgiu da oportunidade visualizada para exportação dos seus produtos para o mercado externo. Sabe-se que para as empresas exportadoras a certificação em sistemas de gestão, especificamente em gestão da qualidade, é quase uma condição sine qua non. Assim, a empresa, em médio prazo, irá buscar a certificação da ISO 9001, a qual facilitaria a comercialização para o exterior.

A implantação de sistemas de gestão segue um modelo de maturidade. Dessa forma, para a implantação de sistemas de gestão da qualidade é necessário, a priori, o desenvolvimento de programas mais simples que criem na empresa a cultura da qualidade. O Programa 5S prepara o caminho para a introdução de programas de qualidade mais avançados. Por isso, antes de dar início ao mapeamento de processos, verificou-se a necessidade de desenvolver o Programa 5S na empresa, promovendo a disciplina através da consciência e responsabilidade de todos, de forma a tornar o ambiente de trabalho agradável, seguro e produtivo.

Nas organizações tradicionais, com diversos níveis hierárquicos, os gerentes são orientados para resultados da sua área de atuação, ou seja, apresentam organização estruturada de forma funcional. Assim, o Departamento de Produção, quando persegue suas metas sem a visão macro da organização, põe em risco o próprio negócio, uma vez que pode criar competição ao invés de cooperação dentro da empresa, já que todos competem pelos mesmos recursos. Esse formato é típico de uma visão estreita e limitada do negócio, uma vez que não contempla o processo como parte de um sistema global. A gerência de processos busca eliminar essas deficiências por meio da aplicação de uma metodologia sistêmica, privilegiando e focando o processo e onde a estrutura hierárquica tem papel unicamente organizacional. Os organogramas são estruturados na vertical, e o atendimento ao cliente é horizontal (CAMPOS, 2009).

Para implantação do gerenciamento por processo, além de levantar informações que orientariam ao longo de todo o projeto, foi necessário realizar diversas reuniões com os colaboradores para divulgar o objetivo do trabalho, bem como conscientizá-los da importância da metodologia para a competitividade da empresa. Inicialmente, definiu-se uma equipe de trabalho, composta por colaboradores indicados pela alta gerência; em seguida, foram definidas as ações de preparação para a implantação da gestão por processos.

Durante o desenvolvimento do projeto houve a necessidade de definir, de forma clara, quais as atribuições de cada cargo que compunha o organograma funcional da empresa. Juntamente com os funcionários da organização, criou-se um documento-padrão que definia as atividades de cada função descrita no organograma. Essa atividade auxiliou no desenvolvimento dos mapas dos processos, os quais devem indicar o responsável por cada atividade sequenciada no processo.

Por se tratar de uma empresa pequena e com poucos anos, a identificação de alguns processos foi complicada, pois os colaboradores não sabiam ao certo como ocorriam as atividades e quais eram as saídas esperadas. Muitas vezes, para agilizar o processo de produção os colaboradores realizavam as atividades que não eram de sua competência, ocasionando, assim, alta variabilidade e, consequentemente, o retrabalho do processo de produção.

O projeto teve sua continuação com a identificação dos processos que compunham a estrutura da empresa, processos tanto do setor produtivo quanto do administrativo. Identificados os processos, delimitaram-se aqueles que eram críticos para o funcionamento da organização, bem como definiu as fronteiras dos processos, os clientes de cada um, os principais inputs e outputs e as atividades envolvidas no fluxo de trabalho.

Entrevistas com os responsáveis pelas várias atividades dentro de um processo e estudos dos documentos disponíveis, a fim de coletar 
informações suficientes para reprodução dos processos no mapeamento, foram realizadas para cada processo identificado como chave. Após essa etapa, ocorreu a criação do mapa do processo, ou o fluxograma do processo, com base nas informações adquiridas; e também definiu-se um responsável por cada processo, ou seja, "o dono do processo". Os fluxogramas foram formatados em um documentopadrão, conforme exemplo do processo de produção do corpo da Estação Meteorológica E1000, apresentado na Figura 1.

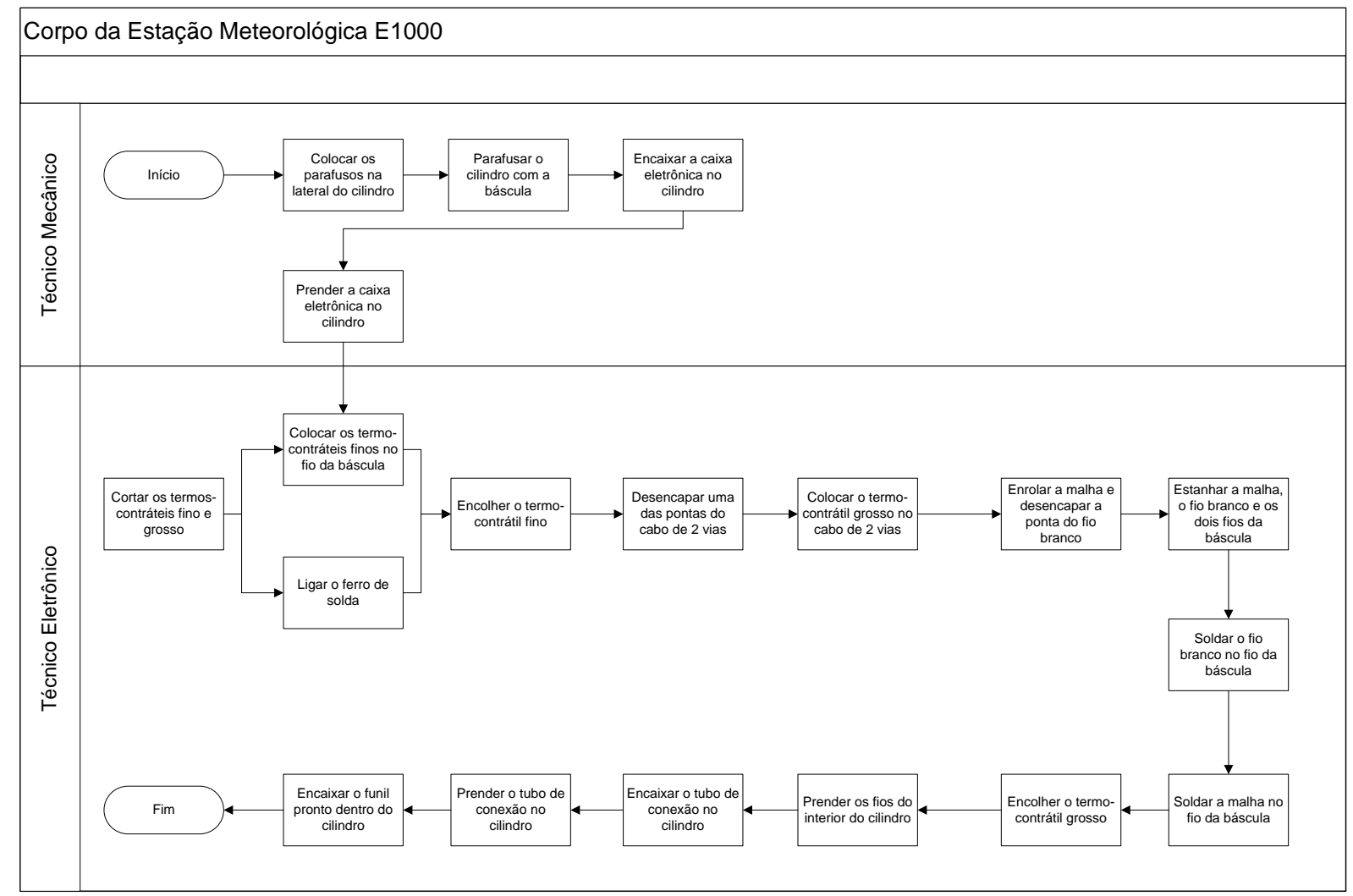

Figura 1 - Mapa do processo de produção do corpo da Estação Meteorológica E1000.

De acordo com Batista et al. (2006), para a construção de um fluxograma ou mapa de processo é preciso que haja uma sequência lógica das atividades produtivas constituintes do processo. A sequência do processo deve ser apresentada, listando-se os símbolos identificadores segundo a ordem de ocorrência e ligando-os por segmentos de reta que representam o fluxo do item. O gráfico da Figura 1 tem início com a entrada dos insumos na empresa e segue em cada passo, como transportes, armazenamentos, inspeções, montagens, até que se tornem um produto acabado ou parte de um subconjunto, registrando o andamento do processo por um ou mais departamentos.
Para dar continuidade à implantação, é necessário validar o processo mapeado. Essa validação foi realizada em uma reunião com todos os envolvidos no processo e, somente após essa etapa, seguia para a elaboração do procedimento operacional padrão.

A partir do desenvolvimento dos fluxogramas, foi possível elaborar os procedimentos operacionais padrão (POP), nos quais as informações sobre os processos e as atividades que o constituem foram descritas de forma bem detalhada. Algumas atividades foram mais bem descritas em instruções de trabalho (IT), conforme exemplo apresentado na Figura 2. 


\begin{tabular}{|c|c|c|c|c|c|c|c|c|c|c|c|c|}
\hline & \multicolumn{5}{|c|}{ Logo Empresa } & \multicolumn{7}{|c|}{ INSTRUÇÃO DE TRABALHO } \\
\hline CÓdIGo & I & $\mathrm{T}$ & $\mathrm{P}$ & $\mathrm{R}$ & 0 & 0 & 0 & 1 & 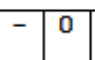 & 7 & \multirow{2}{*}{ ÁREA } & \multirow{2}{*}{ Produção } \\
\hline REVISÄ م & \multicolumn{10}{|c|}{0} & & \\
\hline FOLHA & \multicolumn{10}{|c|}{ Página 1 de 1} & & \\
\hline TITULO & \multicolumn{12}{|c|}{ Soldagem } \\
\hline
\end{tabular}

\begin{tabular}{|l|}
\hline Material necessário: \\
\hline - Ferro de solda \\
- Estanho \\
- Placa eletrônica \\
- Somponentes a serem soldados \\
\hline
\end{tabular}

\begin{tabular}{|c|c|}
\hline \multicolumn{2}{|c|}{$\begin{array}{l}\text { Descrição do procedimento: } \\
\text { - Pegar todos os materiais necessários. } \\
\text { - Eigar o ferro de solda na tomada. } \\
\text { - Viraixar a placa apoiando o componentena mesa. } \\
\text { - Encostar a ponta do ferro de solda como estanho na junção do componente com a placa, com } \\
\text { um ângulo de } 60^{\circ} \text {. } \\
\text { - Derreter levemente o estanho na junção do componente coma pla ca, verificar se a solda está } \\
\text { fria (isto ocorre para resfriamentos rápidos) e puxar a ponta do estanhopara cima. Assim, o } \\
\text { componente ficará preso na placa. Tomar muito cuidado para que a solda não ultrapasse o seu } \\
\text { local destinado, pois esta falha poderá acarretar em um curto-circuitona placa. A ponta do } \\
\text { estanho é puxada para cima justamente para que não se encoste as soldas a o la do. } \\
\text { - Como alicate cortar o restante do pino do componente e a ponta do estanho rente à placa para } \\
\text { não ficar muito alto. } \\
\text { - Devolver todo o material utiliza do, colocando-os em seus devidos lugares. }\end{array}$} \\
\hline & \\
\hline & Aprovação \\
\hline
\end{tabular}

Figura 2 - Instrução de trabalho para a atividade de soldagem, referente ao processo Construção da Caixa Eletrônica.

A utilização de padronização nos processos faz que se tenha o cumprimento adequado das atividades realizadas em uma organização, de tal maneira que cada pessoa tenha condições de assumir a responsabilidade pelos resultados do próprio trabalho. A maneira mais apropriada para se obter desempenho eficaz das funções operacionais é por meio da elaboração dos procedimentos operacionais padronizados (POP), um componente vital em qualquer organização que busque eficiência em seus processos e contribui para a satisfação das exigências dos clientes e a redução de custos de perdas e refugos dos processos (VARGAS et al., 2008).

O POP é um documento que contém a descrição detalhada de todas as operações necessárias para a realização de um procedimento, ou seja, é um roteiro padronizado para realizar uma atividade com o objetivo de alcançar a meta-padrão. Ele pode conter: listagem de equipamentos, peças e materiais utilizados na tarefa, descrição dos procedimentos da tarefa por atividades críticas e roteiro de inspeção periódica dos equipamentos de produção, entre outros. A IT tem como função detalhar o nível de tarefas como a atividade que deve ser realizada em um processo, de forma a descrever um passo a passo para determinada atividade, com o objetivo de garantir uma saída esperada.

Os documentos elaborados durante o projeto auxiliaram na execução das atividades, padronização e manutenção do conhecimento. Os procedimentos operacionais e instruções de trabalho foram escritos de forma detalhada para obtenção de uniformidade de uma rotina operacional, permitindo a verificação de cada uma de suas etapas. Possuíam fácil leitura e foram disponibilizados no local de trabalho para que pudessem ser consultados sempre que necessário. Os funcionários foram conscientizados e treinados sobre a importância de sua atualização. 


\section{Conclusão}

O objetivo principal deste trabalho foi a descrição da implantação da gestão por processos em uma pequena empresa de base tecnológica, de acordo com a norma ISO 9001, identificando, mapeando e validando os processos-chave que fazem parte da empresa. Dessa forma, este trabalho permitiu a elaboração de um conjunto de procedimentos operacionais que resultaram na padronização dos processos e permitiram aumento na produtividade da empresa, de modo que ela iniciasse a obtenção dos requisitos para certificação ISO 9001.

Essa melhoria nos indicadores de produtividade da empresa pode ser comprovada com a redução do tempo para realizar um processo mapeado e, também, do menor número de falhas e, ou, de saídas não desejadas dos processos de produção.

Foram mapeados 32 processos-chave, para os quais os procedimentos operacionais padrões foram descritos, e sete instruções de trabalho foram elaboradas. Esses documentos possibilitaram um padrão de execução das atividades na empresa, aumentando a eficiência dos processos, uma vez que as atividades que não agregavam valor foram eliminadas. A eliminação dessas atividades foi possível por meio das etapas de validação dos processos. Essas etapas abrangeram todos os envolvidos em cada processo, de forma que uma análise completa da sequência de atividades foi realizada, comparando-se com a saída desejada e também com os requisitos dos clientes do processo.

No início do trabalho, os colaboradores entendiam o Programa 5S apenas como forma de organizar e limpar o ambiente de trabalho, limitando-se descartar alguns utensílios, organizar e limpar o que sobrou. Por isso, inúmeras vezes tiveram que ser conscientizadas, o que se tratava de uma mudança de cultura dentro da organização. $\mathrm{O}$ grande desafio foi a disciplina, pois os colaboradores relaxavam e, com o tempo, a empresa voltaria a ser o que sempre foi, ficando claro que não houve mudança de cultura, que é fundamental para o sucesso e manutenção do programa.

A gestão por processos é uma metodologia necessária para a implantação e manutenção de sistemas de gestão da qualidade, pois facilita a compreensão da organização como um todo, ou seja, a visão sistêmica, destacando-se os processos que realmente agregam valor ao negócio e colocando o cliente como parte integrante deles.
Com o envolvimento e comprometimento de todas as áreas da organização que participam do processo, tanto no momento de redefinição dos processos quanto também na sua melhoria contínua, há um substancial aumento na motivação dos colaboradores, pois estes ficam sabendo da sua importância para os processos da organização e melhoria na produtividade.

\section{Referências}

ASSOCIAÇÃO BRASILEIRA DE NORMAS TÉCNICAS. NBR ISO 9001:2008 - Sistema de gestão da qualidade: Requisitos. Rio de Janeiro, 2008. 24 p.

BATISTA, G. R.; LIMA, M. C. C.; GONÇALVES, V. S. B.; SOUTO, M. S. M. L. Análise do processo produtivo: um estudo comparativo dos recursos esquemáticos. In: ENCONTRO NACIONAL DE ENGENHARIA DE PRODUÇÃO - ENEGEP, 26., 2006, Fortaleza. Resumos... Fortaleza, 2006.

CAMPOS, V. F. Gerência da qualidade total: estratégia para aumentar a competitividade da empresa brasileira. Belo Horizonte: Fundação Cristiano Ottoni, 1989.

CAMPOS, J. P. Mapeamento de processos: uma estratégia vencedora. Ábaco Curos, 2009. Disponível em: <http://www.abacocursos.com.br/download/artigo_ 08.pdf>. Acesso em: 16 nov. 2010

CAMPOS, V. F. Qualidade total - Padronização de empresas. Belo Horizonte: Fundação Cristiano Otoni, 1994.

CARPINETTI, L. C. R.; MIGUEL, P. A. C.; GEROLAMO, M. C. Gestão da qualidade ISO 9001:2000 - Princípios e requisitos. São Paulo: Atlas, 2007.

CARVALHO, Marly Monteiro; PALADINI, Edson Pacheco. Gestão da qualidade: teoria e casos. Rio de Janeiro: Elsevier, 2005.

CHEN, W. S.; CHYU, C. C. A minimum setup strategy for sequencing PCBs with multi-slot feeders. Integrating Manufacturing Systems, p. 255-267, 2003.

COLENGHI, V. M. O\&M e qualidade total: uma integração perfeita. Rio de Janeiro: Qualitymark. 2007. 
ETZIONI, A. Sociologia industrial: o estudo das organizações econômicas. In: _ (Org.). Organizações complexas. São Paulo: Atlas, 1981.

GARVIN, David A. Gerenciando a qualidade: a visão estratégica e competitiva. Rio de Janeiro: Qualitymark, 2002.

GHOBADIAN, A.; GALLEAR, D. Total quality management in SMEs. Omega, v. 24, n. 1, 1996.

GONÇALVES, José Ernesto Lima. As empresas são grandes coleções de processos. In. RAE Revista de Administração de Empresas, v. 40, n. 1, p. 6-9, jan./mar. 2000.

JURAN, J. M.; GRYNA, F. M. Controle da qualidade. São Paulo: Makron Books, 1993.

LEE, C. Y.; ZHOU, X. Quality management and manufacturing strategies in China. International Journal of Quality \& Realiability Management, v. 17, n. 8, p. 876-899, 2000.

LIMA, R. Procedimento operacional padrão - A importância de se padronizar tarefas nas BPLC. Belém, 2005. (Curso de BPLC).

MAXIMIANO, A. C. A. Introdução à administração. São Paul: Atlas, 2006.

MIGUEL, P. A. C. Estudo de caso na engenharia de produção: estruturação e recomendações para sua condução. Revista Produção, v. 17, n. 1, p. 216229, jn./abr. 2007.

PROCACI, I. B.; SUZUKI, J. A.; FARIA, A. F. Aplicação do EVTECIAS na criação de spin-off academic. In: ENCONTRO MINEIRO DE ENGENHARIA DE PRODUÇÃO, 6., 2010, Coronel Fabriciano, MG. Resumos... Coronel Fabriciano, MG, 2010.

SINGLES, J.; RUEL, G.; VAN DE WATER, H. ISO 9000 series: certification and performance. International Journal of Quality \& Realiability Management, v. 18, n. 1, p. 62-75, 2001.

SARTORELLI, L. E. Análise crítica da implantação da ISSO 9001/1994 com alguns requisitos da ISSO 9001:2000 à luz dos principais autores da qualidade. 2003. Dissertação (Mestrado em Engenharia Mecânica) Universidade Estadual de Campinas, Campinas, SP, 2003.
SLACK, N.; CHAMBERS, R. J.; JOHNSTON, R. Administração da produção. São Paulo: Atlas, 2002.

SOUZA, J. P.; TANABE, C. H. Barreiras a implantação da norma ISO 9001:2000 em empresas do setor metalmecânico da região de Maringá/PR. Caderno de Administração, v. 14, n. 2, p. 46-56, 2006.

STEVENSON, W. J. Administração das operações de produção. Rio de Janeiro: LTC, 2001.

TOLEDO, J. C.; CARPINETTI, L. C. R. Gestão da qualidade. In: ROZENFELD, Henrique; BANAS, Elizabeth (Org.). A fábrica do futuro. São Paulo: Banas, 2000.

VARGAS, J. O.; ALMEIDA, A. M. D. P.; VIEIRA, J. G. V.; FARIA, A. F. Análise dos procedimentos operacionais padronizados em um centro de distribuição de uma indústria alimentícia. In: ENCONTRO MINEIRO DE ENGENHARIA DE PRODUÇÃO - EMEPRO, 4., 2008, Ouro Preto, MG. Resumos... Ouro Preto, MG, 2008.

YAMANAKA, L. Proposta para implementação conjunta de um sistema da qualidade ISO 9001:2000 em empresas do aglomerado de Sertãozinho. 2008. 285 f. Dissertação (Mestrado em Engenharia de Produção) - Universidade de São Paulo, São Carlos, SP, 2008.

$\mathrm{ZU}, \mathrm{X}$. Infrastructure and core quality management practices: how do they affect quality? International Journal of Quality \& Realiability Management, v. 26, n. 2, p. 129-149, 2009.

Artigo selecionado entre os 10 melhores do VII Encontro Mineiro de Engenharia de Produção - EMEPRO 2011. 